\title{
Author Correction: Increased human and economic losses from river flooding with anthropogenic warming
}

Francesco Dottori@, Wojciech Szewczyk, Juan-Carlos Ciscar, Fang Zhao, Lorenzo Alfieri, Yukiko Hirabayashi, Alessandra Bianchi, Ignazio Mongelli, Katja Frieler, Richard A. Betts (10 and Luc Feyen

Correction to: Nature Climate Change https://doi.org/10.1038/s41558-018-0257-z, published online 20 August 2018.

In the version of this Letter originally published, the affiliation for Yukiko Hirabayashi was mistakenly given as 'Institute of Industrial Science, The University of Tokyo, Bunkyō, Japan'. It should have read 'Department of Civil Engineering, Shibaura Institute of Technology,

Tokyo, Japan'. This has now been corrected.

Published online: 11 September 2018

https://doi.org/10.1038/s41558-018-0292-9

\section{Author Correction: Re-examining tropical expansion}

Paul W. Staten, Jian Lu $\mathbb{D}$, Kevin M. Grise $\mathbb{B}$, Sean M. Davis and Thomas Birner

Correction to: Nature Climate Change https://doi.org/10.1038/s41558-018-0246-2, published online 30 August 2018.

In the version of this Review originally published, the affiliations for author Sean M. Davis were incomplete. An additional affiliation, "Cooperative Institute for Research in Environmental Sciences, University of Colorado at Boulder, Boulder, Colorado, USA", has now been added.

Published online: 8 October 2018

https://doi.org/10.1038/s41558-018-0323-6

\section{Author Correction: Microbial temperature sensitivity and biomass change explain soil carbon loss with warming}

Tom W. N. Walker (D), Christina Kaiser, Florian Strasser, Craig W. Herbold, Niki I. W. Leblans, Dagmar Woebken (D), Ivan A. Janssens, Bjarni D. Sigurdsson and Andreas Richter (DD

Correction to: Nature Climate Change https://doi.org/10.1038/s41558-018-0259-x, published online 17 September 2018.

In the version of this Letter originally published, the name of the institute in affiliation 3 was incorrect; it read "Institute of Applied Systems Analysis" but should have read "International Institute for Applied Systems Analysis". This has now been corrected.

Published online: 8 October 2018

https://doi.org/10.1038/s41558-018-0322-7 